\title{
BMJ Open Previous sickness absence and current low perceived social support at work among employees in the general population: a historical cohort study
}

\author{
Marit Knapstad, ${ }^{1,2}$ Kristina Holmgren, ${ }^{3}$ Gunnel Hensing, ${ }^{3}$ Simon $\varnothing v e r l a n d d^{2,4}$
}

To cite: Knapstad M, Holmgren K, Hensing G, et al. Previous sickness absence and current low perceived social support at work among employees in the general population: a historical cohort study. BMJ Open 2014;4:e005963. doi:10.1136/bmjopen-2014005963

- Prepublication history for this paper is available online. To view these files please visit the journal online (http://dx.doi.org/10.1136/ bmjopen-2014-005963).

Received 24 June 2014 Revised 20 August 2014 Accepted 22 August 2014

CrossMark

\footnotetext{
${ }^{1}$ Department of Health

Promotion and Development, University of Bergen, Bergen, Norway

${ }^{2}$ Department of Public Mental Health, Norwegian Institute of Public Health, Bergen,

Norway

${ }^{3}$ Department of Public Health and Community Medicine, The Sahlgrenska Academy, Gothenburg University, Gothenburg, Sweden

${ }^{4}$ Department of Psychosocial Science, University of Bergen, Bergen, Norway
}

Correspondence to Marit Knapstad; marit.knapstad@uib.no

\section{ABSTRACT}

Objective: Although sickness absence often is a process over time, most studies have treated the phenomenon as a discrete event and focused more on its causes than its consequences. We aimed to examine whether various patterns of previous longterm sickness absence were associated with current low perceived social support at work.

Method: This is a historical cohort study based on data from a population-based survey among Swedish employees $(n=2581)$. The survey data were linked to official registries yielding data on sickness absence 17 years prior to the survey.

Results: The main finding was that previous sickness absence was associated with current low perceived social support at work. The highest odds for low social support were found among those who had a stable high level of sickness absence. The two indicators of perceived social support employed were somewhat differently associated with previous sickness absence: Recency of absence showed to be of importance for general support at the workplace and the relationship with colleagues and superiors. Experiencing that one's immediate superior rarely or never regards one's view was, on the other hand, mainly related to having had a high level of sickness absence, irrespective of recency.

Conclusions: Our results indicate that recency and extent of previous sickness absence are related to perceived social support at work. Future research on the relationship between social support and sickness absence should use repeated measurements and acknowledge the possible bidirectional relationship.

\section{INTRODUCTION}

In many cases, sickness absence is a process over time that may carry its own consequences for the individual. ${ }^{1}$ Prolonged and repeated sickness absence is a precursor for future sickness absence, ${ }^{2}$ unemployment, work termination ${ }^{3}$ and disability pension ${ }^{4} 5$; these associations cannot be explained by deterioration in health alone. ${ }^{6}$ Sickness absence can mean deprivation of an

\section{Strengths and limitations of this study}

- This is the first study to explore how previous sickness absences are associated with current perceived social support at work.

- The participants were drawn from the general population and included employees across different work settings.

- Information on previous sickness absence was based on 7 years of registry information. This minimises problems with attrition and response bias, and allows examination of timing and extent of previous sickness absence in relation to current social support.

- Social support was only measured at one time point, precluding adjustments for baseline status as well as investigating degree of stability in perceived social support at work.

- Participation-rates were lower among men, younger individuals, those with lower incomes and those born outside Nordic countries.

important social arena, with social marginalisation, isolation and exclusion as possible results. $^{7-9}$ Two Swedish studies have found long-term sickness absentees to report far more negative consequences of their sickness absence than positive ones, such as negative effects on health, sleep, mental well-being, ${ }^{8}$ salary, career possibilities and zest for work. ${ }^{9}$ The vast majority of studies on sickness absence have, however, treated the phenomenon as a discrete event, and aimed to identify its causes more than its consequences. ${ }^{1}$

Social support affects health ${ }^{10}$ and social support at work is one of the work characteristics extensively studied in relation to sickness absence. Although an employee's relationships with colleagues and superiors can be considered to be more formal than his or her relationships with family and friends, the social network at work can be an important source of support for the employee, especially considering the hours 
spent at work and the importance of work in Western societies. ${ }^{1112}$ Low support is found to be associated with later sickness absence in studies across several cohorts, ${ }^{13-16}$ and is observed in the public as well as private sector, ${ }^{17}$ and includes support levels from coworkers as well as superiors. ${ }^{18-20}$ Experiencing justice and fairness through, for instance, experiencing being listened to by one's immediate superior, is another aspect of social support found associated with being on sickness absence. ${ }^{21}$ Social support is also relevant for employees returning to work after being on sick leave. ${ }^{22} 23$

There is increased awareness of the possible reversed or reciprocal relationship between work conditions and health, that is, that health through various mechanisms might influence work characteristics or that these factors affect each other bidirectionally. ${ }^{24} \mathrm{~A}$ recent review study concluded that the relationship between job demandcontrol-support and job-related well-being might partly be reciprocal or reverse,${ }^{25}$ and a four-wave study found evidence for a reciprocal causal relationship between work characteristics, including social support and mental health. ${ }^{26}$ Studies challenging a unidirectional relationship between social support and sickness absence are scarce. One Swedish study found that long-term absentees often reported that their absence affected their sense of belonging to the workgroup negatively, especially if full-time absent. ${ }^{9}$ The cross-sectional design of that study, however, precludes making inferences about the temporal relationship between work absence and social inclusion at work.

In summary, few studies have examined patterns of sickness absence and their correlates. It is possible that sickness absence sets negative social processes in motion and that these difficulties add to the troubles causing the sickness absence in the first place and challenges returning to and retaining work. To increase understanding of these social processes, the aim of this study is to examine whether various patterns of previous longterm sickness absence are associated with current low perceived social support at work in a longitudinal analysis. We will include two measures of social support at work and explore the relevance of subitems of the social support scale employed.

\section{METHOD}

\section{Study design and participants}

This is a historical cohort study linking data from the Health Assets Project (HAP) survey in 2008 to official registries of sickness absence 1-7 years prior to the HAP survey. HAP was specifically designed to gain knowledge about the influence of individual, organisational and societal factors on health, sickness absence and return to work. The target population in HAP comprised individuals aged 19-64 in Västra Götaland in Western Sweden, a region with urban and rural areas and a population of 1.6 million (17\% of the Swedish population). More details about HAP are described elsewhere. ${ }^{27} \mathrm{~A}$ random sample was extracted from Statistics Sweden April 2008 ( $\mathrm{n}=7984)$ and invited to participate. Data were collected using registry data and a postal questionnaire including items on sociodemographic factors, physical and mental health, issues concerning sickness absence, work and family conditions, life events, leisure and lifestyle. The participation rate was $50.4 \%(\mathrm{n}=4027)$. A dropout analysis showed a significant higher dropout rate in the youngest age group (19-30 years of age), those with the lowest income level ( $\leq 149$ 000SEK), as well as among those born outside Nordic countries. In the present study, we excluded those younger than 23 years of age in $2008(\mathrm{n}=277)$, those reporting not being employed when participating in the survey $(\mathrm{n}=1090)$, those registered with sickness compensation in 2008 who did not answer any of the items regarding social support $(n=14)$, and those with missing data on sickness absence for one or more of the follow-up years 2001-2007 $(n=65)$. The final study sample was $n=2581$.

\section{Measures}

Predictor: sickness absence history 2001-2007

Using personal identification numbers, survey data were linked to the 'Longitudinal integrated database for sickness insurance and labour market research', Statistics Sweden (LISA) records on sickness absence. In the Swedish insurance system, the employer covers sickness benefit the first 14 days of a sickness absence spell (except not counting one qualifying day); thereafter, benefits are granted from the Social Insurance Agency and registered in LISA. For the self-employed and those without employment (eg, unemployed and students), the sickness benefit is paid and registered from day 2 . LISA comprises information on an individual's total number of registered sickness absence days per year. Some participants $(n=86)$ were granted sickness compensation or activity compensation one or more of the years after this benefit arrangement was established in 2003. As these benefits are awarded for severe and lasting work disability, we coded the number of absence days as full-time sickness absence ( 365 days) for the calendar year a person received a sickness or activity compensation benefit. We excluded those with missing data on sickness absence on one or more of the follow-up years $(n=65)$, since many of these were probably out of risk for sickness absence due to migration. These cases were nonetheless at risk at least some of the follow-up years and some missing data could be caused by registration error and regarded as random. To check the robustness of our results, we ran a sensitivity analysis in which we included the cases and treated missing data through multiple imputations. Results were similar across solutions (data not shown).

On the basis of information from the LISA-register, we constructed groups with different patterns of previous sickness absence to relate them to current perceived social support. Initially, we performed exploratory latent class analyses (LCA), a statistical technique suitable for 
finding meaningful subgroups in a population, which are similar, for example, in their growth trajectories. ${ }^{28}$ Owing to difficulties in including the subgroup with sickness compensation in the LCA and low power due to small categories if excluding this subgroup, we chose to instead construct groups based on median splits, informed by the observations of the LCA; First, as suggested from the LCA, we split the follow-up period from 2001 to 2007 into a 'distant' (2001-2004) and 'recent' (2005-2007) period. Then we calculated the participants' total number of registered sickness absence days for each period. Again for each of the periods, the participants' absence was coded as low ('0') or high (' 1 ') by a median split on the total sickness absence days. This allowed us to construct the following five mutually exclusive categories (see table 1 for overview of categorisation criteria): (1) 'no absence'; no registered sickness absence during the whole period, (2) 'stable low'; a total number of sickness absence days below the median in both of the periods, (3) 'distant high'; above the median in the 'distant' period, and below the median in the recent; (4) 'recent high'; below the median in the 'distant' period, and above the median in the 'recent'; and finally, (5) 'stable high'; above the median on number of sickness absence days in the 'distant' as well as the 'recent' period. The results employing the described grouping yielded similar results as with the more fine-tuned groupings compiled through LCA (data not shown). The sickness absence patterns were, in addition, similar to those that had emerged from a previous published trajectory analysis. ${ }^{29}$

\section{Outcome: social support at work 2008}

Two measures of perceived social support were employed: a workplace social support indicator and a question on immediate superior support.

First, a workplace social support indicator was constructed from the support subscale in the Swedish Demand-Control-Support Questionnaire (DCSQ). ${ }^{30}$ The scale is based on Johnson and Halls' model ${ }^{11}$ and focuses on the atmosphere at work. The participants were asked to what extent they agreed (agree; agree to

Table 1 Categories of previous registered sickness absence 2001-2007

\begin{tabular}{|c|c|c|}
\hline Category & $\begin{array}{l}\text { Sickness absence } \\
\text { during 2001-2004 }\end{array}$ & $\begin{array}{l}\text { Sickness absence } \\
\text { during } 2005-2007\end{array}$ \\
\hline Reference & No sickness absence & No sickness absence \\
\hline Stable low & $\begin{array}{l}\text { Sickness absence } \\
\text { below median split }\end{array}$ & $\begin{array}{l}\text { Sickness absence } \\
\text { below median split }\end{array}$ \\
\hline Distant high & $\begin{array}{l}\text { Sickness absence } \\
\text { above median split }\end{array}$ & $\begin{array}{l}\text { Sickness absence } \\
\text { below median split }\end{array}$ \\
\hline Recent high & $\begin{array}{l}\text { Sickness absence } \\
\text { below median split }\end{array}$ & $\begin{array}{l}\text { Sickness absence } \\
\text { above median split }\end{array}$ \\
\hline Stable high & $\begin{array}{l}\text { Sickness absence } \\
\text { above median split }\end{array}$ & $\begin{array}{l}\text { Sickness absence } \\
\text { above median split }\end{array}$ \\
\hline
\end{tabular}

some extent; disagree to some extent; disagree) to the following six statements: "The atmosphere at my workplace is calm and pleasant"; "The collegiality at work is good"; "People at work understand that I can have a bad day"; "I get along well with my superiors"; "I get along well with my colleagues". Answers were coded 1-4 and summarised giving a scale from 6 to 24 where a higher score denoted higher social support (Cronbach's $\alpha=0.86$ ). The scale was found to have satisfactory psychometric properties. ${ }^{31}$ A principal component analysis supported a one-factor solution in our data. Owing to non-normal distribution and in order to identify high versus low level of social support, the total score was split by the median. A sensitivity analysis was performed, treating the scale continuously in log-transformed regression analyses, which gave similar results. In addition, we performed sub-analyses for each item of social support to explore which aspects were most relevant in relation to sickness absence history (each item dichotomised yielding a low ('disagree to some extent' or 'disagree') and a high ('agree to some extent' or 'agree') support category).

Second, we included a single-item measure on immediate superior support: "Does your immediate superior consider your views?" (Yes, frequently; yes, sometimes; no, rarely; no, never/almost never; no, I don't have a manager). Answers were dichotomised, giving a high (yes, frequently; yes, sometimes) and a low (no, rarely; no, never/almost never) support group. Participants responding that they did not have a superior were excluded from the analyses regarding this outcome $(\mathrm{n}=6)$.

\section{Demographic variables}

The following demographic factors were extracted from Statistics Sweden: Gender (male, female), age (mean), gross income (SEK $\leq 149000,150$ 000-299 000, $\geq 300$ 000) and occupational class (unskilled-skilled manual, lowintermediate non-manual, higher non-manual and entrepreneurs). Level of education (elementary or less, upper secondary, higher) and type of employment (temporary, permanent) was self-reported.

\section{Analyses}

We employed MPlus to perform the initial exploratory LCA analyses. The remaining analyses were performed in Stata 12. Differences in background characteristics (gender, age group, income level, occupational class, education level and type of employment) between employees with different sickness absence histories were examined using $\chi^{2}$ tests and analysis of variance. Further, median (IQR) days per year of previous sickness absence were calculated. In the latter calculations, individuals on sickness and activity compensation during follow-up were excluded, as we did not have their exact number of absence days registered. Then we examined whether each of the two social support outcomes could be predicted by previous sickness absence, building 
multivariate logistic regression models. For both models, we first tested for crude associations, before including candidate confounders (gender, age, income, occupational class, education, type of employment). Only variables found relating to exposure and outcome in the data $(p<0.05)$ were included in the final model (age in social support scale; age, education and occupational class for immediate superior support outcome). Finally, to explore the relevance of different aspects of social support, we performed subanalyses where we treated each of the subitems of the social support scale as separate outcomes.

We employed multiple imputations to handle missing data using the multivariate normal model procedure in Stata 12, with 20 cycles of imputation. All variables reported in the study in addition to variables on health and well-being were included as auxiliary variables to perform the imputation, where missing responses were substituted by predictions based on valid responses from all other variables (see table 2 for magnitude of internal missing per variable). The variables were subsequently rounded to the original scale to enable multinomial regression analyses and Allison's ${ }^{32}$ recommended procedure was followed for nominal variables with more than two categories.
RESULTS

\section{Characteristics of employees with various sickness} absence histories

The total sample was $n=2581$, of whom $55.2 \%$ were women and mean (SD) age was 45.1 (11.2). Of these, $1535(59.5 \%)$ had no registered sickness absence during the 7 years follow-up period prior to the survey. Of the 1046 who had at least one episode of registered sickness absence in this period, $521(20.2 \%)$ were categorised as having a 'stable low' absence pattern, 198 (7.7\%) as 'distant high', $150(5.8 \%)$ as 'recent high' and finally, $177(6.9 \%)$ were categorised as 'stable high' (see operationalisation in method section). Median (IQR) sickness absence days per year in the first (2001-2004) and second (2005-2007) follow-up periods were as follows in the groups: 'Stable low': 6(19)/1(16); 'distant high': 127 (197)/0(9); 'recent high': $0(7) / 177(259)$; and 'stable high': $212.5(299) / 277.5(366)$ in the first/second periods, respectively.

The proportion of women was higher in the groups with sickness absence than in the group with no sickness absence, especially 'distant high' and 'stable high'. Mean age was highest in the 'stable high' group and lowest in the 'no absence' group. The groups with sickness absence had lower levels of education, occupational

Table 2 Description of employees in a general working population sample with various histories of registered sickness absence (2001-2007)

\begin{tabular}{|c|c|c|c|c|c|}
\hline & $\begin{array}{l}\text { No absencet } \\
n=1535\end{array}$ & $\begin{array}{l}\text { Stable low } \\
\mathrm{n}=521\end{array}$ & $\begin{array}{l}\text { Distant hight } \\
\mathrm{n}=198\end{array}$ & $\begin{array}{l}\text { Recent hight } \\
n=150\end{array}$ & $\begin{array}{l}\text { Stable hight } \\
\mathrm{n}=177\end{array}$ \\
\hline \multicolumn{6}{|l|}{ Gender $(\%)^{\star}$} \\
\hline Women & 48.6 & 62.2 & 71.2 & 64.0 & 71.8 \\
\hline Age (mean (SD))* & $44.1(11.5)$ & $45.8(10.7)$ & $47.5(10.5)$ & $46.9(11.1)$ & $50.4(9.4)$ \\
\hline \multicolumn{6}{|l|}{ Level of education (\%)* } \\
\hline Higher education & 45.3 & 33.6 & 33.9 & 34.6 & 33.3 \\
\hline Upper secondary & 41.6 & 42.6 & 42.9 & 46.0 & 35.6 \\
\hline Elementary or less & 12.6 & 22.3 & 22.2 & 18.7 & 30.5 \\
\hline Missing & 0.5 & 1.5 & 1.0 & 0.7 & 0.6 \\
\hline \multicolumn{6}{|l|}{ Occupational class $(\%)^{*}$} \\
\hline Higher non-manual, Entrepren. & 22.8 & 10.5 & 15.1 & 10.7 & 10.2 \\
\hline Intermediate-low non-manual & 43.4 & 39.2 & 36.9 & 44.0 & 37.3 \\
\hline Skilled—unskilled manual & 32.2 & 48.2 & 46.5 & 44.0 & 49.2 \\
\hline Missing & 1.6 & 2.1 & 1.5 & 1.3 & 3.4 \\
\hline \multicolumn{6}{|l|}{ Income $(\%)^{\star}$} \\
\hline$\geq 300000$ SEK & 41.2 & 29.0 & 27.3 & 27.3 & 17.5 \\
\hline 150 000-299 000SEK & 49.3 & 63.9 & 62.6 & 68.0 & 73.5 \\
\hline$\leq 149000$ SEK & 9.5 & 7.1 & 10.1 & 4.7 & 9.0 \\
\hline \multicolumn{6}{|l|}{ Form of employment (\%) } \\
\hline Permanent job & 91.7 & 91.5 & 90.4 & 91.4 & 90.4 \\
\hline Temporary job & 7.2 & 7.3 & 8.1 & 7.3 & 8.5 \\
\hline Missing & 1.1 & 1.2 & 1.5 & 1.3 & 1.1 \\
\hline
\end{tabular}

Bivariate associations examined using $\chi^{2}$ tests for categorical and ANOVA for continuous variables. Missing responses are handled using pairwise deletion.

${ }^{*} \mathrm{p}<0.001$.

†No absence: no registered sickness absence days (SA, ie, beyond 14 days) during the follow-up period 2001-2007. Stable low: SA below the median split 2001-2007. Distant high: SA above the median split 2001-2004 and below the median split 2005-2007. Recent high: SA below the median split 2001-2004 and above the median split 2005-2007. Stable high: SA above the median split 2001-2007.

ANOVA, analysis of variance. 
Table 3 Effect of previous sickness absence on current low perceived social support at work and low perceived immediate superior support

\begin{tabular}{|c|c|c|c|c|c|}
\hline \multirow{2}{*}{$\begin{array}{l}\text { Sickness } \\
\text { absence } \\
\text { history }^{*}\end{array}$} & & \multicolumn{2}{|c|}{$\begin{array}{l}\text { Low social } \\
\text { support }\end{array}$} & \multicolumn{2}{|c|}{$\begin{array}{l}\text { Low superior } \\
\text { support }\end{array}$} \\
\hline & & $\overline{\text { OR }}$ & $95 \% \mathrm{Cl}$ & OR & $95 \% \mathrm{Cl}$ \\
\hline \multirow[t]{2}{*}{ Stable low } & & & & & \\
\hline & & & & & \\
\hline \multirow[t]{2}{*}{ Distant high } & & & & & \\
\hline & & & & & \\
\hline \multirow[t]{2}{*}{ Recent high } & & & & & \\
\hline & & & & 1.8 & \\
\hline \multirow[t]{2}{*}{ Stable high } & & & & 2.0 & \\
\hline & & & & .1 & \\
\hline \multicolumn{6}{|c|}{$\begin{array}{l}\text { ssion analyses, crude and adjusted models. } \\
\text { s absence history group is contrasted to those with } \\
\text { sickness absence (reference group). } \\
\text { onses handled using multiple imputations. } \\
\text { : no registered sickness absence days (SA, ie, } \\
\text { ys) during the follow-up period } 2001-2007 \text {. Stable } \\
N \text { the median split } 2001-2007 \text {. Distant high: SA } \\
\text { dian split } 2001-2004 \text { and below the median split } \\
\text { Recent high: SA below the median split 2001-2004 } \\
\text { e median split 2005-2007. Stable high: SA above the } \\
2001-2007 \text {. } \\
\text { age in analysis on social support index as outcome, } \\
\text { for age, education and work class in the analysis on } \\
\text { e superior support. }\end{array}$} \\
\hline
\end{tabular}

class and income than the 'no absence' group. There was, on the other hand, no association between employment type and history of sickness absence (table 2).

\section{Current perceived low overall social support at work in} relation to various patterns of previous sickness absence Those having a 'recent high', 'stable high' and 'stable low' sickness absence history had increased odds for reporting low overall level of perceived social support at work compared to those without a history of sickness absence. Effects were somewhat higher for the two former than for the latter group, albeit with overlapping CIs (crude $\mathrm{OR}=1.7,95 \%$ CI 1.2 to 2.4 ; OR=1.5, $95 \%$ CI 1.1 to 2.1 ; and $\mathrm{OR}=1.3,95 \%$ CI 1.0 to 1.6 , respectively). Adjusting for confounders hardly altered the effect sizes. There was no difference in social support between those in the 'distant high' group and those with no sickness absence (table 3).

\section{Current perceived low immediate superior support in relation to various patterns of sickness absence}

Those having a 'distant high', 'recent high' or 'stable high' sickness absence history had increased odds for reporting that their immediate superior rarely or never considers their views, compared to those having no previous sickness absence (adjusted $\mathrm{OR}=2.1$, 95\% CI 1.4 to 3.2; $\mathrm{OR}=1.8,95 \%$ CI 1.1 to 2.9 ; and $\mathrm{OR}=2.1,95 \%$ CI 1.3 to 3.3 , respectively). There was no difference between the 'stable low' group and those with no history of sickness absence (table 3 ).

\section{Aspects of current perceived social support at work in relation to various patterns of sickness absence}

When analysing each single item of perceived social support separately, the 'stable high' group followed by the 'recent high' had the overall highest odds for experiencing low social support, albeit with overlapping CIs compared to the effects of the other sickness absence groups. These two were also the only groups significantly associated with the items "I do not get along well with my superiors" and "I do not get along well with my colleagues" (table 4). The item with the overall highest effect size across sickness absence groups was "My colleagues are not there for me" (table 4), while the single association with the highest effect size was between the 'stable high' group and the item "The atmosphere at my workplace is not calm and pleasant" $(\mathrm{OR}=2.9,95 \% \mathrm{CI}$

Table 4 Effect of previous sickness absence patterns (2001-2007) on single-items regarding current social support at work (2008)

\begin{tabular}{|c|c|c|c|c|c|c|c|c|c|c|c|c|}
\hline \multirow{2}{*}{$\begin{array}{l}\text { Sickness absence } \\
\text { history* }^{*}\end{array}$} & \multicolumn{2}{|c|}{$\begin{array}{l}\text { The } \\
\text { atmosphere } \\
\text { at my } \\
\text { workplace is } \\
\text { not calm and } \\
\text { pleasant }\end{array}$} & \multicolumn{2}{|c|}{$\begin{array}{l}\text { The } \\
\text { collegiality at } \\
\text { work is not } \\
\text { good† }\end{array}$} & \multicolumn{2}{|c|}{$\begin{array}{l}\text { My } \\
\text { colleagues } \\
\text { are not there } \\
\text { for met }\end{array}$} & \multicolumn{2}{|c|}{$\begin{array}{l}\text { People at } \\
\text { work do not } \\
\text { understand } \\
\text { that I can } \\
\text { have a bad } \\
\text { dayt }\end{array}$} & \multicolumn{2}{|c|}{$\begin{array}{l}\text { I do not } \\
\text { get along well } \\
\text { with my } \\
\text { superiors }\end{array}$} & \multicolumn{2}{|c|}{$\begin{array}{l}\text { I do not } \\
\text { get along well } \\
\text { with my } \\
\text { colleaguest }\end{array}$} \\
\hline & $\overline{\text { OR }}$ & $95 \% \mathrm{Cl}$ & OR & $95 \% \mathrm{Cl}$ & $\overline{\text { OR }}$ & $95 \% \mathrm{Cl}$ & OR & $95 \% \mathrm{CI}$ & $\overline{\text { OR }}$ & $95 \% \mathrm{Cl}$ & OR & $95 \% \mathrm{Cl}$ \\
\hline Stable low & 1.2 & 1.0 to 1.6 & 1.7 & 1.3 to 2.3 & 2.3 & 1.6 to 3.2 & 1.4 & 1.1 to 1.9 & 1.2 & 0.8 to 1.7 & 1.5 & 0.9 to 2.4 \\
\hline Distant high & 1.9 & 1.3 to 2.6 & 1.4 & 0.9 to 2.3 & 1.2 & 0.7 to 2.3 & 0.9 & 0.6 to 1.5 & 1.3 & 0.7 to 2.3 & 0.9 & 0.4 to 2.1 \\
\hline Recent high & 1.6 & 1.0 to 2.3 & 1.5 & 0.9 to 2.6 & 2.7 & 1.6 to 4.6 & 1.2 & 0.7 to 2.0 & 1.8 & 1.0 to 3.2 & 2.3 & 1.2 to 4.4 \\
\hline Stable high & 2.5 & 1.8 to 3.5 & 2.9 & 1.9 to 4.5 & 2.6 & 1.6 to 4.4 & 1.7 & 1.1 to 2.6 & 1.9 & 1.1 to 3.3 & 2.5 & 1.4 to 4.7 \\
\hline
\end{tabular}


1.9 to 4.5$)$. The 'distant' group showed non-significant associations to all items except the item "The collegiality at work is not good" (table 4).

\section{DISCUSSION}

Main results

The main finding of this study was that previous sickness absence was associated with current low perceived social support at work. The highest odds for low social support were found among those who had a stable high level of sickness absence. Interestingly, our two indicators of perceived social support were somewhat differently associated with previous sickness absence; while recency of absence showed to be of importance for general support at work and relationship with colleagues and superiors, experiencing low immediate superior support was mainly related to having had a high level of sickness absence, irrespective of recency.

\section{Strengths and limitations}

One of the main strengths of this study was the linkage between a population-based health survey and registries of sickness absence up to 7 years prior to the survey. The many and comparable data points on sickness absence enabled inclusion of the time aspect as well as extent of previous sickness absence in our analyses. Only a handful of studies have examined the impact of having a history of sickness absence and even fewer have taken the time aspect into consideration. The use of register data on sickness absence minimised problems with attrition and response bias. Gathering data on exposure and outcome from different sources further decreased the risk of response bias. The social support scale is a commonly used instrument in Scandinavia and is found to have good psychometric properties. ${ }^{31}$ Finally, the general population design allowed the study of employees across different work settings, increasing generalisability of the results.

The following limitations also need to be considered. As with other population-based surveys, non-participation and selective participation remains a challenge, with lower participation-rates in the current study among men, younger individuals, those with lower incomes and those born outside the Nordic countries.

A key limitation is that social support was only measured at one time point, precluding adjustments for baseline status as well as investigating degree of stability in support at work. Low social support at baseline might have contributed to elevated sickness absence in the first place, as demonstrated in several studies. $^{13-15}{ }^{18}$ Nonetheless, our data on sickness absence goes back 7 years from the time point measuring social support at work. If our results indicate that employees had problems regarding social support at work 7 years back already, the results arguably pinpoint a central issue regarding sickness absence. The study may also be considered a first step to investigate the possible bidirectional or reciprocal causal relationship of the much more studied association between social support at work and sickness absence. ${ }^{24}$ Further studies employing a multiwave design are suggested to examine the quality of the association, such as degree of reciprocity, in more detail.

Immediate superior support was measured employing a single item with unknown psychometric properties and should be interpreted with caution. A factor analysis merging the item with the support scale supported a one-factor solution, however, the item was in general less correlated with the other items than the correlations between the items in the established scale (data not shown). Further, the two measures aim at different theoretical constructs, the former regarding atmosphere ${ }^{30}$ and the latter fairness/justice/participation at the workplace. $^{33}$ To not distort the quality of the scale and to explore various aspects of social support, we chose to analyse the single item separately.

The measure of previous sickness absence was rather crude, including the total number of registered sickness absence days (beyond 14 days if employed) per year. One should hence be cautious generalising our results to patterns of shorter spells, as analyses of more finetuned fluctuations in sickness absences might show different qualities and correlates. Being able to detect significant differences between the sickness absence groups using a crude measure increases our confidence in that a true association exists between previous sickness absence and social support at work.

From July 2003 to December 2004 the employercovered period was extended from 14 to 21 days in Sweden, ${ }^{34}$ yielding slightly different inclusion criteria for LISA registration during this period compared to the rest of the follow-up period. However, a sensitivity analysis excluding data from 2003 to 2004 did not change the overall findings (data not shown).

The relationship between sickness absence and social support might show different patterns between men and women, as found in some studies examining the opposite direction of this association. ${ }^{13}{ }^{14}{ }^{18}$ Small sickness absence groups constrained the use of gender-stratified or interaction analyses. There were no differences in social support between men and women in the data, suggesting that gender differences do not explain the associations found. Gender differences, however, cannot be ruled out and, considering the high sickness absence rate among women, further studies specifically investigating explanations for this gender gap are warranted.

\section{Interpretation}

This is the first study that we know of to examine the association between previous sickness absence and current perceived social support at the workplace in a longitudinal design. The results add to the small literature illustrating that a unidirectional approach to the relationship between psychosocial work conditions and measures of health, such as sickness absence, is inadequate. $^{25} 26$ The findings further harmonise with 
Sieurin's descriptive study, ${ }^{9}$ which showed that many long-term absentees, especially those full-time absent, experienced that their absence negatively affected their sense of belonging to the workgroup. We did not differentiate between full-time and part-time absence in our study. Nonetheless, the odds for low perceived social support at work were generally higher for those with a high level of absence than for those with lower levels of absence. This difference may suggest that keeping some contact with the workplace during sickness absence is beneficial to maintain social inclusion at work, while acknowledging that the expedience of contact may vary, for example, with cause of absence. ${ }^{35}$ Social support at work might also be seen as part of the push and pull factors that motivate an individual to be present or absent from work. ${ }^{36}$ We can only speculate about the wider consequences of the potential negative impact of sickness absence on social support at work, as suggested by our results. A conceivable consequence is that it contributes to negative processes that increase risk of lasting work exclusion by challenging return to work or contributing to further episodes of sickness absence.

While a high level of absence in recent years was associated with current low perceived social support at work, a high level of absence some years ago was not. This may indicate a time aspect in the association. One explanation of this 'time effect' is that the association between recent absence and social support reflects an effect of ongoing work conditions on sickness absence, as examined and found in previous studies. ${ }^{20}$ However, a sensitivity analysis censoring those on sickness absence on time of participation only reduced the effect sizes to some extent, leaving this interpretation only partly supported by the data (data not shown). An alternative interpretation is that sickness absence actually affects social support at work, but only if the absence is relatively recent: First, sickness absence can add strain on coworkers, thereby draining their goodwill, and this problem may increase with length of sickness absence, as described by coworkers themselves in a Swedish qualitative study. ${ }^{37}$ Such interpretation further fits well with the results showing that the single-item with the overall highest effect-size across pattern of previous sickness absence was experiencing that colleagues were not there for them. The finding illustrates that the relationship with colleagues may be highly relevant to take into account in return to work processes after long-term absences. ${ }^{37}$ Second, the nonsignificant association between the 'distant high' sickness absence group and current perceived social support could mean that these individuals have sorted out their situation, especially regarding their colleagues, either through successful social reintegration or by changing work place or task. More studies are required to replicate our findings and to gain better understanding of how sickness absence can affect social inclusion at work.

Experiencing that one's immediate superior rarely or never regarded one's view did, on the other hand, not depend on recency, but on whether one had a history with high level of sickness absence at all. This could partly be a result of a downward selection process, where those with a high level of absence drift towards less favourable jobs with lower opportunities for discretion. ${ }^{38}$ Interestingly, the association between level of absence and immediate superior support was not explained by sociodemographic factors such as occupational class or income. Bearing in mind the possibility of residual confounding, the uncertainties regarding causality and the use of a single-item outcome, the finding could suggest that sickness absence has an independent effect on job status or the experience of being treated with justice and fairness. The finding is worth further investigation, as there are promising results on the role of superior support in improving return to work: though findings are not unequivocal across health conditions ${ }^{23}$ and gender, ${ }^{39}$ superior support is found to predict return to work in a systematic review on patients with low back pain ${ }^{22}$ as well as in a controlled study on worker-superior communication among long-term absentees due to burn out. ${ }^{40}$

Factors other than the sickness absence as such, for instance, mental health factors and personality, might have contributed to the association between sickness absence and social support at work found in the current study. It could, for instance, be that workers with mental illnesses are at greater risk of low social support than workers with less stigmatised illnesses. Further, workers with depression and anxiety have described that they tend to distort work tasks, which again may depreciate their relationship with colleagues. ${ }^{41}$ The associations between social support and mental health, depression and personality are complex. Low perceived social support at work is found to be a risk factor for depression, but depression and negative affectivity may also affect a worker's perception of and interaction with their work environment. ${ }^{42}$ Further, though results are inconclusive, ${ }^{16}$ a partial reverse causation in the association between psychosocial working condition and mental well-being has been suggested..$^{25}$ The cross-sectional measurement of these variables restricted investigating these aspects in our study. Further studies measuring each variable of interest at several time points may clarify the mechanisms involved in more detail.

\section{CONCLUSION}

Results showed that recency and extent of previous sickness absence were both related to current perceived social support at work. The findings illustrate that sickness absence may have negative consequences for social inclusion at the workplace. Nevertheless, it does also point to the need for more research using individual repeated measurements, under which the impact of sickness absence for social inclusion and integration at work could be interesting to trace out in more detail.

Acknowledgements The authors thank Tore Tjora for supervising the initial latent class analyses.

Contributors MK contributed to conception and design of the study, analysed the data, interpreted the data and drafted the manuscript and consequent 
revisions regarding important intellectual content. $\mathrm{KH}, \mathrm{GH}$ and $\mathrm{S} \emptyset$ contributed to conception and design of the study, interpretation of the data and critical revisions of the manuscript for important intellectual content. All authors approved of the final version of the manuscript.

Funding The data collection was financed by the Swedish Social Insurance Agency.

Competing interests None.

Patient consent Obtained.

Ethics approval The HAP study was approved by the Ethics Committee, University of Gothenburg, Sweden, registration number 039-08.

Provenance and peer review Not commissioned; externally peer reviewed.

Data sharing statement No additional data are available.

Open Access This is an Open Access article distributed in accordance with the Creative Commons Attribution Non Commercial (CC BY-NC 4.0) license, which permits others to distribute, remix, adapt, build upon this work noncommercially, and license their derivative works on different terms, provided the original work is properly cited and the use is non-commercial. See: http:// creativecommons.org/licenses/by-nc/4.0/

\section{REFERENCES}

1. Vingard E, Alexanderson K, Norlund A. Chapter 9. Consequences of being on sick leave. Scand J Public Healt 2004;32(63 Suppl):207-15

2. Dekkers-Sanchez PM, Hoving JL, Sluiter JK, et al. Factors associated with long-term sick leave in sick-listed employees: a systematic review. Occup Environ Med 2008;65:153-7.

3. Virtanen M, Kivimaki M, Vahtera J, et al. Sickness absence as a risk factor for job termination, unemployment, and disability pension among temporary and permanent employees. Occup Environ Med 2006;63:212-17.

4. Lund T, Kivimaki M, Labriola M, et al. Using administrative sickness absence data as a marker of future disability pension: the prospective DREAM study of Danish private sector employees. Occup Environ Med 2008;65:28-31.

5. Wallman T, Wedel H, Palmer E, et al. Sick-leave track record and other potential predictors of a disability pension. A population based study of 8,218 men and women followed for 16 years. BMC Public Health 2009;9:104.

6. Hultin $\mathrm{H}$, Lindholm C, Moller J. Is There an association between long-term sick leave and disability pension and unemployment beyond the effect of health status?-A Cohort Study. PLoS ONE 2012;7:e35614

7. Bryngelson A. Long-term sickness absence and social exclusion. Scand J Public Healt 2009;37:839-45.

8. Floderus B, Goransson S, Alexanderson K, et al. Self-estimated life situation in patients on long-term sick leave. J Rehabil Med 2005;37:291-9

9. Sieurin L, Josephson M, Vingard E. Positive and negative consequences of sick leave for the individual, with special focus on part-time sick leave. Scand J Public Healt 2009;37:50-6.

10. Holt-Lunstad J, Smith TB, Layton JB. Social Relationships and mortality risk: a meta-analytic review. PLoS Med 2010;7:e1000316.

11. Johnson JV, Hall EM. Job strain, work place social support, and cardiovascular disease: a cross-sectional study of a random sample of the Swedish working population. Am J Public Health 1988;78:1336.

12. House JS. Work stressors and social support. Addison-Wesley, editor. Reading, MA: Addison-Wesley, 1981.

13. North FM, Syme SL, Feeney A, et al. Psychosocial work environment and sickness absence among British civil servants: the Whitehall II Study. Am J Public Health 1996;86:332-40.

14. Melchior M, Niedhammer I, Berkman L, et al. Do psychosocial work factors and social relations exert independent effects on sickness absence? A six year prospective study of the GAZEL cohort. $J$ Epidemiol Commun H 2003;57:285-93.

15. Moreau M, Valente F, Mak R, et al. Occupational stress and incidence of sick leave in the Belgian workforce: the Belstress study. $J$ Epidemiol Commun H 2004:58:507-16.

16. Foss L, Gravseth HM, Kristensen $\mathrm{P}$, et al. Risk factors for long-term absence due to psychiatric sickness: a register-based 5-year follow-up from the Oslo health study. J Occup Environ Med2010;52:698-705.

17. Lidwall $U$, Marklund $\mathrm{S}$. What is healthy work for women and men?A case-control study of gender- and sector-specific effects of psycho-social working conditions on long-term sickness absence. Work 2006;27:153-63.

18. Stansfeld SA, Rael EGS, Head J, et al. Social support and psychiatric sickness absence: a prospective study of British civil servants. Psychol Med 1997;27:35-48.

19. Oxenstierna G, Ferrie J, Hyde M, et al. Dual source support and control at work in relation to poor health. Scand J Public Healt 2005;33:455-63.

20. Vahtera J, Kivimäki M, Pentti J, et al. Effect of change in the psychosocial work environment on sickness absence: a seven year follow up of initially healthy employees. J Epidemiol Commun $H$ 2000;54:484-93.

21. Holmgren K, Hensing G, Dellve L. The association between poor organizational climate and high work commitments, and sickness absence in a general population of women and men. J Occup Environ Med 2010;52:1179-85.

22. Steenstra I, Verbeek J, Heymans M, et al. Prognostic factors for duration of sick leave in patients sick listed with acute low back pain: a systematic review of the literature. Occup Environ Med 2005;62:851-60.

23. Brouwer S, Reneman MF, Bültmann U, et al. A prospective study of return to work across health conditions: perceived work attitude, selfefficacy and perceived social support. J Occup Rehabil 2010;20:104-12.

24. de Lange $\mathrm{AH}$, Taris TW, Kompier MA, et al. "The very best of the millennium": longitudinal research and the demand-control(support) model. J Occupational Health Psychol 2003;8:282-305.

25. Hausser JA, Mojzisch A, Niesel M, et al. Ten years on: a review of recent research on the Job Demand-Control (-Support) model and psychological well-being. Work Stress 2010;24:1-35

26. De Lange AH, Taris TW, Kompier MAJ, et al. The relationships between work characteristics and mental health: examining normal, reversed and reciprocal relationships in a 4-wave study. Work Stress 2004;18:149-66.

27. Hensing $\mathrm{G}$, Holmgren $\mathrm{K}$, Mårdby $\mathrm{A}$. Harmful alcohol habits were no more common in a sample of newly sick-listed Swedish women and men compared with a random population sample. Alcohol Alcohol 2011;46:471-7.

28. Muthén BO. Latent variable analysis: growth Mixture modeling and related techniques for longitudinal data. In: Kaplan D. ed. The SAGE Handbook of Quantitative Methodology for the social sciences. Park CA: Sage, 2004:346-70.

29. Haukka E, Kaila-Kangas L, Ojajärvi A, et al. Pain in multiple sites and sickness absence trajectories: a prospective study among Finns. Pain 2013;154:306-12.

30. Landsbergis $\mathrm{P}$, Theorell T, Schwartz J, et al. Measurement of psychosocial workplace exposure variables. Occup Med-State Art 2000;15:163-88.

31. Sanne B, Torp S, Mykletun A, et al. The Swedish Demand-ControlSupport Questionnaire (DCSQ): factor structure, item analyses, and internal consistency in a large population. Scand J Public Healt 2005;33:166-74.

32. Allison PD. Missing data. Thousand Oaks, CA: Sage, 2002.

33. Hellrieg D, Slocum JW. Organizational climate-Measures, research and contingencies. Acad Manage J 1974;17:255-80.

34. Statistics-Sweden. Integrated database for labour market research [Longitudinell integrationsdatabas för Sjukförsäkrings- och Arbetsmarknadsstudier (LISA) 1990-2009]. 2011.

35. MacEachen E, Clarke J, Franche RL, et al. Systematic review of the qualitative literature on return to work after injury. Scand J Work Env Health 2006;32:257-69.

36. Johansson $\mathrm{G}$. The illness flexibility model and sickness absence. Stockholm: Karolinska Institutet, 2007.

37. Tjulin A, Maceachen E, Stiwne EE, et al. The social interaction of return to work explored from co-workers experiences. Disabil Rehabil 2011;33:1979-89.

38. de Lange AH, Taris TW, Kompier MAJ, et al. Different mechanisms to explain the reversed effects of mental health on work characteristics. Scandinavian J Work Env Health 2005;31:3-14.

39. Holmgren K, Ekbladh E, Hensing G, et al. The Combination of Work Organizational Climate and Individual Work Commitment Predicts Return to Work in Women But Not in Men. J Occup Environ Med 2013;55:121-7.

40. Karlson B, Jonsson P, Palsson B, et al. Return to work after a workplace-oriented intervention for patients on sick-leave for burnout--a prospective controlled study. BMC Public Health 2010;10:301.

41. Bertilsson M, Petersson EL, Ostlund G, et al. Capacity to work while depressed and anxious - a phenomenological study. Disabil Rehabil 2013;35:1705-11.

42. Stansfeld S, Candy B. Psychosocial work environment and mental health-a meta-analytic review. Scand J Work Env Health 2006;32:443-62. 